\title{
Utilization of date juice for the production of lactic acid by streptococcus thermophilus
}

\begin{abstract}
The interest in the fermentative production of lactic acid has increased due to the prospects of environmental friendliness and of using renewable resources instead of petrochemicals. In this context, we have judged that is gainful to use the date juice which is with a low commercial value as a substrate for the production of lactic acid by Streptococcus thermophilus. Further, dates are rich in sugar ranging from $65 \%$ to $80 \%$ on dry weight basis mostly of inverted form (glucose and fructose), which can used as carbon source for the fermentation and the production of microbial biomass. The parameters optimization for lactic acid production by $S$. thermophilus grown on medium based on dates in order to improve yields is applied in this study. The results showed that the maximum of lactic acid production $(36.9 \mathrm{~g} / 1)$ is obtained after the enrichment of date juice with yeast extract (15\%), Tween $80(1 \mathrm{~g} / 1) \mathrm{MgSO}_{4}(0.5 \mathrm{~g} / 1)$, $\mathrm{MnSO}_{4}(0.02 \mathrm{~g} / \mathrm{l})$ and $\mathrm{K}_{2} \mathrm{HPO}_{4}(1 \mathrm{~g} / \mathrm{l})$.
\end{abstract}

Keywords: lactic acid production, date juice, streptococcus thermophilus
Volume 3 Issue 3 - 2017

\author{
Bouhadi D,' Raho B, ${ }^{2}$ Hariri A,' Benattouche \\ Z,' Sahnouni F,' Ould Yerou K,' Bouallam SA ${ }^{4}$ \\ 'Department of Science the Nature and Life, University of \\ Mascara,Algeria \\ ${ }^{2}$ Department of Health and Proteomics, University of Sidi Bel- \\ Abbès, Algeria \\ ${ }^{3}$ Department of Science, University of Oran, Algeria \\ ${ }^{4}$ Department of Nature and Life, University of Mascara,Algeria
}

Correspondence: Bouhadi D, Bioconversion Laboratory, Microbiology Engineering and Health Safety, faculty of Science the Nature and Life, University of Mascara,Algeria,

Email bouhadidjilali@yahoo.fr

Received: October 18, 2016 | Published: June 23, 2017

\section{Introduction}

Lactic acid is one of the most important organic acids which are being extensively used around the globe in a range of industrial and biotechnological applications. ${ }^{1}$ It is widely used in the food, cosmetic, pharmaceutical, and chemical industries and has received increased attention for use as a precursor for the biodegradable plastic polylactic acid, used in medical, industrial, and consumer products. ${ }^{2}$ Lactic acid can be produced commercially by either chemical synthesis or microbial fermentation. ${ }^{3}$ The production by fermentation process has attracted interest due to its advantages compared with chemical synthesis such as production of pure isomers $(\mathrm{L}(+)$ or $\mathrm{D}(-)$ lactic acid), use of renewable and low cost raw materials, low energy consumption and mild operation conditions. ${ }^{4}$ There are many cheap and renewable raw materials in the form of starch (corn, wheat, potato, cassava, rice, sweet sorghum) and lignocelluloses (corn cobs, waste paper and woody materials) can be used as a substrate for fermentation of lactic acid. ${ }^{5}$ Renewable resources do not give any net contribution of carbon dioxide to the atmosphere, as do the limited oil and fossil-fuel-based sources. Lactic acid can be biosynthesized by some bacteria and filamentous fungi. ${ }^{4}$

Algeria have a rich biodiversity of about 1900 date cultivars, but $30 \%$ of the production of dates is characterized by a low commercial quality. ${ }^{6}$ Beside direct consumption of the whole dates, the fruits are traditionally used to prepare a wide range of product such as date juice concentrates (spread, syrup and liquid sugar), fermented date products (vinegar, organic acids) and date pastes for different uses e.g. bakery and confectionary. Date fruits are considered as a good source of sugars. It provides natural sugar in the form of glucose and fructose,${ }^{7}$ which could be used as carbonaceous source of fermentation for the production of the lactic acid. The aim of the present study is the valorisation of the dates by production of its juice and used it as medium for the development of $S$. thermophillus and the production of lactic acid.

\section{Materials and methods}

\section{Plant material}

The date palm of Ghars cultivars grown in Bechar, South-western of Algeria were used for this study. The samples were collected during May 2014 season, cleaned, placed in polyethylene bags, and stored in refrigerator until analysis.

\section{Bacterial strains and growth conditions}

Streptococcus thermophilus is a commonly used starter bacterium in dairy industry. The test strain was purchased from Giplait (dairy unit) of Mascara (Algeria) which is used for the manufacture of yogurt. The strain was inoculated in tubes with $10 \mathrm{ml}$ of sterile skimmed milk using $1 \%$ inoculum and incubated at $30^{\circ} \mathrm{C}$ until the coagulation of milk, then streaked on M17 agar. ${ }^{8}$ The enrichment of $S$. thermophilus was carried out using M17 broth.

\section{Preparation of date syrup}

Date flesh (Semi-dry) Ghars variety was crushed and cut to small pieces and dry-blended. Two and $1 / 2$ liters of hot water at $80-85^{\circ} \mathrm{C}$ were added to $1 \mathrm{~kg}$ of date, homogenized and filtered through a cloth. The collected raw date juice was then centrifuged at $15,000 \mathrm{rpm}$ for $10 \mathrm{~min}$. The produced date syrup was used as culture medium. The syrup is fixed in a pH between 6-6.5 and sterilized during 20 minutes at $120^{\circ} \mathrm{C}$.

\section{Fermentation conditions}

Batch cultivations were performed in Erlen of $250 \mathrm{ml}$ with a working volume of $100 \mathrm{ml}$, with M17 medium and incubated for $42^{\circ} \mathrm{C}$ for $24 \mathrm{~h}$. Fed-batch cultivations were equally carried out in a reactor having a capacity of five liters provided with all the accessories. The $\mathrm{pH}$ value of the cultures was automatically maintained at 6.2 by atomic addition, and the temperature was maintained at $42^{\circ} \mathrm{C}$ for $24 \mathrm{~h}$. 
The biomass evolution, sugar consumption and lactic acid production are followed at regular time intervals.

\section{Analytical methods}

Sugar content was analyzed as glucose by the phenol sulfuric acid method of. ${ }^{9}$ The biomass was estimated by measuring the optical density at $620 \mathrm{~nm}$. Kinetic of growth: We take off every two hours until 28hours $10 \mathrm{ml}$ of medium of fermentation and we read it by a spectrophotometer at $620 \mathrm{~nm}$. By this way, we determine, the latency phase, the exponential phase of growth, the rate of growth and time of generation. Total acidity, expressed as percent lactic acid, was determined by titrating with $0.02 \mathrm{~N} \mathrm{NaOH} .{ }^{10}$ and. ${ }^{11}$

\section{Results and discussion}

The figure shows the growth profiles $\left(\mathrm{OD}_{620}\right)$ of carbohydrate consumption and lactate production in the optimized medium and in the M17 medium. Streptococcus thermophilus strain develops immediately without latency phase and reached the stationary phase after $13 \mathrm{~h}$ of culture in the optimized medium while it reached this period in M17 medium just after 10-20h. On the one hand, biomass profiles are similar during active growth phase, but a perceptible difference in the final biomass. Finally, for the both studied cultures, the maximum biomass (DO) coincides with the consumption of the majority of the carbon substrate (sugars $=8.11 \mathrm{~g} / 1$ in the 24 hours of fermentation). It also appears that the growth and production lactic acid is inhibited when the $\mathrm{pH}$ falls to 4.23 in M17 medium and 4.63 in the optimized medium. This is due to the strong acidity resulting from the accumulation of lactic acid (Figure $1 \& 2$ ).${ }^{12}$ Concluded that the inhibition may be due to carbon source depletion. But in our work, this is not the case, because the consumed sugars concentration equal $44.41 \mathrm{~g} / 1$, so it remains $8.11 \mathrm{~g} / 1$ of sugars in the optimized medium not consumed by the bacteria. From these results, we find that the sugar consumption profile and the lactic acid and biomass production during the batch fermentation of the optimized medium with date juice is similar to the M17. The comparison of the kinetics of the two curves shows that the optimized medium effectively improves the production of lactic acid with a final concentration of $46.26 \mathrm{~g} / 1$ while the M17 medium produced only $36.9 \mathrm{~g} / \mathrm{l}$.

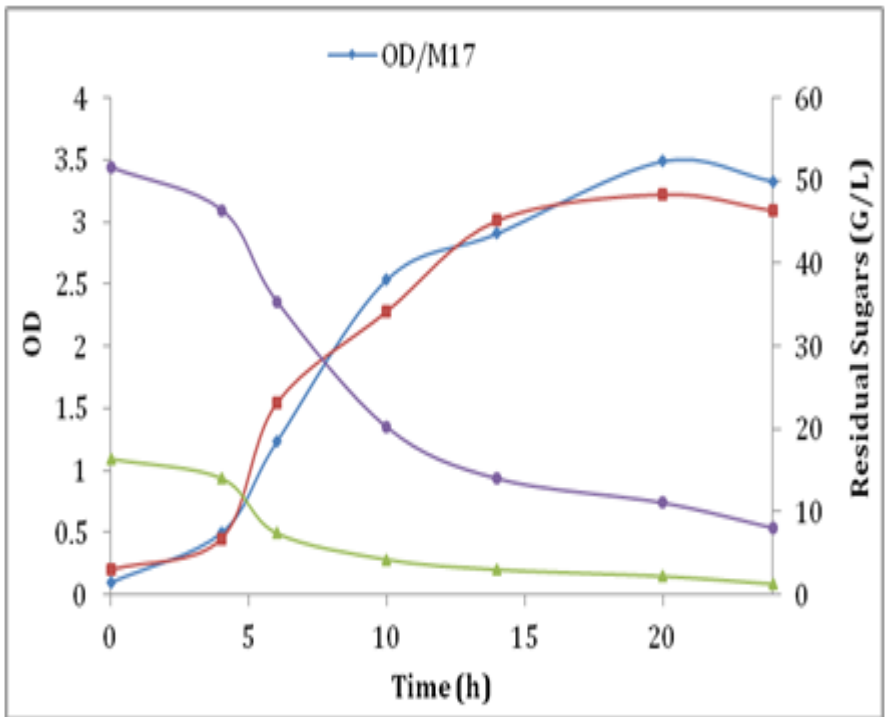

Figure I Evolution of the optical density and sugars.

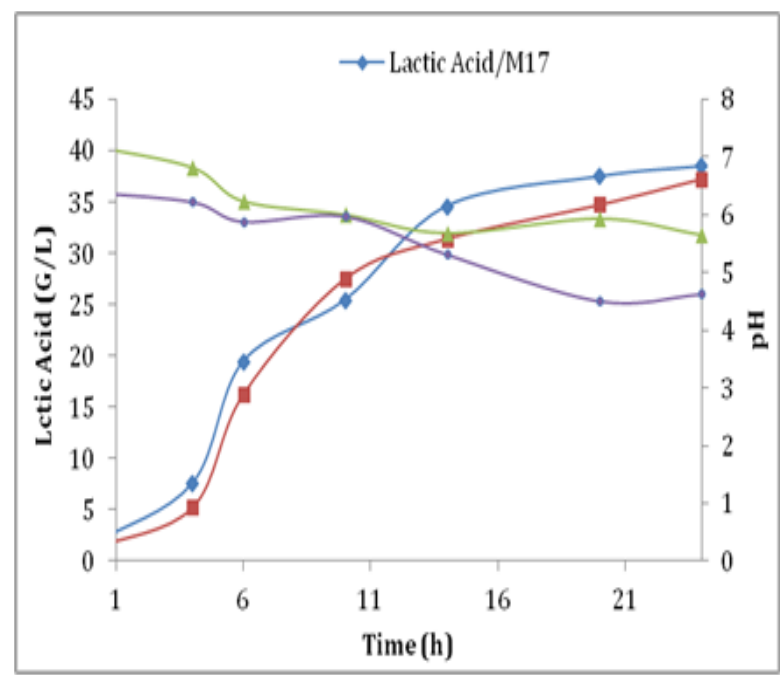

Figure 2 Evolution of $\mathrm{pH}$ and lactic acid production.

\section{The specific growth rate}

The specific rate of growth profiles $(\mu)$ of $S$. thermophilus on the M17 and optimized media medium are illustrated in Figure 3. The results of the specific growth rate $\mu$ showed positive values. At the beginning of the fermentation, the specific rate of growth of $S$. thermophilus, inoculated on an optimized culture medium was zero and reached a maximum value of $1.09 \mathrm{~h}^{-1}$. In contrary, the culture of $S$. thermophilus in M17 medium showed that the specific growth rate is low in the first hours of fermentation and reached a maximum value of $0.73 \mathrm{~h}^{-1}$.

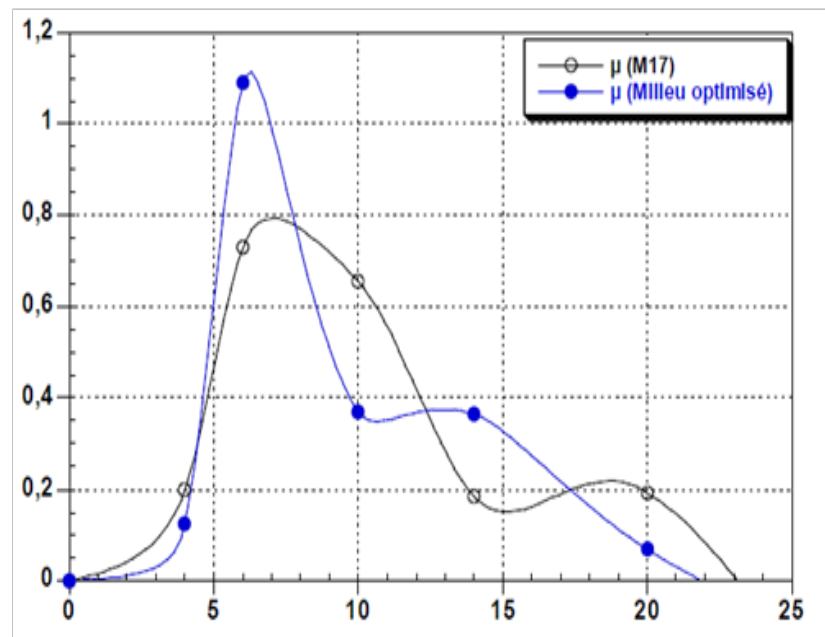

Figure 3 Evolution of specific growth rate $\mu$ in $\mathrm{h}^{-1}$ in MI7 medium and optimized medium.

\section{The specific rate of lactic acid production}

The specific rates of lactic acid production of both fermentations on M17 and optimized medium showed identical maximum values of about $11.02 \mathrm{~g} / \mathrm{gh}$, overlapping, decrease and cancel after 22 hours of fermentation (Figure 4)

\section{The specific rate of substrate consumption}

The evolution of sugar contents is opposed to the amount of 
biomass and lactic acid. S. thermophilus ferments the sugars in the culture medium by glycolysis pathway and produces lactic acid. The comparing of the two rates of the sugar consumption when using the optimized medium of culture and M17 culture medium for $S$. thermophilus growth showed the values of 11.02 and $6.66 \mathrm{~g} / \mathrm{gh}$ respectively (Figure 5).

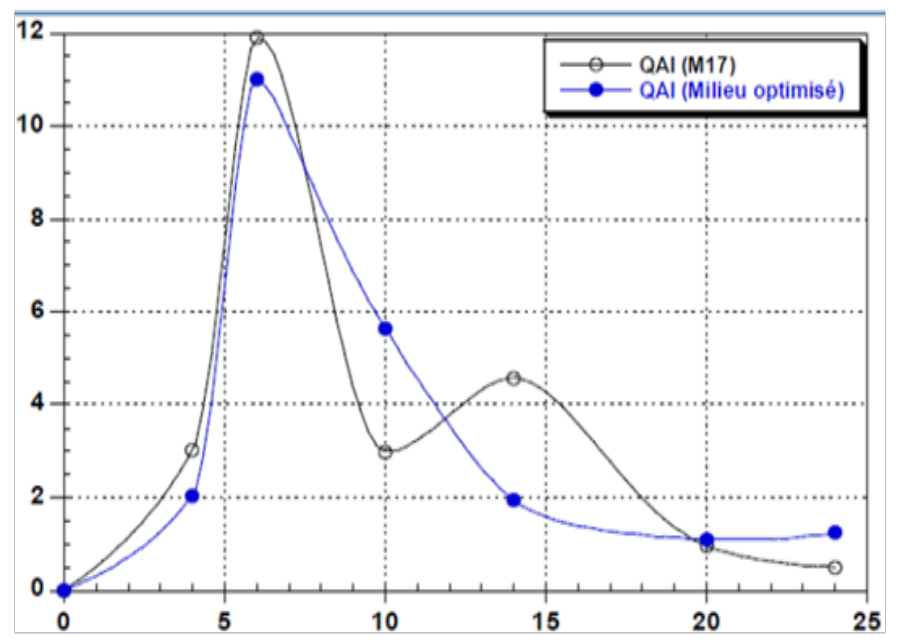

Figure 4 Evolution specific rate of lactic acid production $\mathrm{QAL}$ in g/gh in MI7 medium and optimized medium.

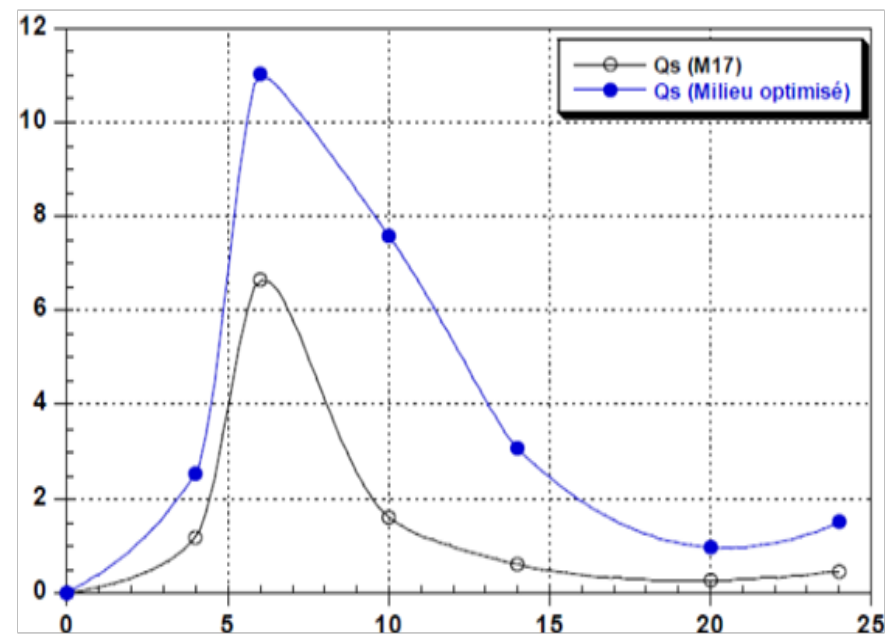

Figure 5 Evolution of specific rates of sugar consumption in g/gh in MI7 medium and in the optimized medium of $S$. thermophilus.

\section{Conclusion}

The results obtained show that the $S$. thermophilus can produce up to $36.9 \mathrm{~g} / \mathrm{L}$ lactic acid by medium based on date juice fortified with yeast extract, Tween $80, \mathrm{MgSO}_{4}, \mathrm{MnSO}_{4}$ and $\mathrm{K}_{2} \mathrm{HPO}_{4}$. Finally, an economic study to the cost of a kilogram lactic acid produced on date juice is justified in order to compare it with other plant products.

\section{Acknowledgements}

None.

\section{Conflict of interest}

The author declares no conflict of interest.

\section{References}

1. Ghaffar T, Irshad M, Anwar Z, et al. Recent trends in lactic acid biotechnology: A brief review on production to purification. Journal of Radiation Research and Applied Sciences. 2014;7(2):222-229.

2. Passos ML, Ribeiro CP. Innovation in Food Engineering: New Techniques and Products. Contemporary Food Engineering. Australia: CRC Press; 2016. 120 p.

3. Theron MM, Lues JFR. Organic Acids and Food Preservation. USA: CRC Press; 2010. 340 p

4. Komesu A, Martins P, Oliveira J, et al. Purification of lactic acid produced from sugarcane molasses. Chemical Engineering Transactions. 2014;37:367-372.

5. Bayitse R. Lactic acid production from biomass: prospect for bioresidue utilization in ghana: technological review. International Journal of Applied Science and Technology. 2015;5(1):164-174.

6. Abekhti A, Zarour K, Boulal A, et al. Evaluation of microbiological quality of the date fruit product "Btana" produced in Adrar South Algeria. Journal of Microbiology Research. 2013;3(5):163-170.

7. Acourene S, Kaoutrher D, Ahmed B, et al. Dates quality assessment of the main date palm cultivars grown in algeria. Annual Research \& Review in Biology. 2014;4(3):487-499.

8. Novel G. Les bactéries lactiques in «Microbiolgie industrielle» Les microorganism d intérêt industrielle. Ed Techniques et documentation. Lavoisier, Italy; 1993. p. 171-215.

9. Dubois M, Gilles KA, Hamilaton JK, et al. Colorimetric method for determination of sugars and related substances. Anal Chem. 1956;28(3):350-356.

10. Audigie CL, Fagerella J, Zonszain F. Manupulation d'analyse biochimique. Edition Tec et Doc, Lavoisier, Italy: 1984. 270 p.

11. Djilali B, Bouziane A, Ahmed H, et al. Study of the behaviour of lactobacillus delbrueckii subsp. bulgaricus in date syrup in batch fermentation with controlled pH. J Biotechnol Biomaterial. 2012;2(2):1-5.

12. Amrane A. Lactic acid production during the associated and the deceleration growth phases of Lactobacillus helviticus cultivated in various conditions and media. Physiology, metabolism. 2001;81:91-103.

13. Gourchala F, Ouazouaz M, Mihoub F, et al. Compositional analysis and sensory profile of five date varieties grown in south Algeria. J Chem Pharm Res. 2015;7(2):511-518. 